\title{
5. A DINÂMICA DA NEOLIBERALIZAÇÃO E OS ATAQUES À SEGURIDADE SOCIAL NO BRASIL*
}

Robson Roberto da Silva

O neoliberalismo surgiu logo após a Segunda Guerra Mundial na região da Europa ocidental e da América do Norte. Um dos principais idealizadores dessa reação foi Friedrich August Von Hayek, que em 1944 publicou o livro chamado O Caminho da Servidão, no qual defendia que a intervenção estatal levaria ao totalitarismo e prejudicaria a liberdade do mercado e dos comércios. A ascensão do neoliberalismo ocorreu no final dos anos 1970 como resposta a crise estrutural do capital, por meio de uma série de idas e vindas e de experimentos desiguais, que buscaram ser ajustados através da criação em 1989, na capital dos Estados Unidos, de uma nova ortodoxia conhecida como Consenso de Washington. Essa ortodoxia resultou da participação de um encontro com várias instituições privadas, diversos economistas latino-americanos, funcionários do Fundo Monetário Internacional (FMI), do Banco Mundial, do Banco Interamericano de Desenvolvimento (BID) e do Tesouro dos Estados Unidos; e incluiu dez medidas consideradas por esses sujeitos como universais e que foram sendo impostas, principalmente aos países periféricos. São elas: disciplina fiscal; redução dos gastos públicos; reforma tributária; juros de mercado; regime cambial de mercado; liberalização comercial; eliminação de controle sobre o investimento direto estrangeiro; privatização; desregulação de leis trabalhistas; e institucionalização da propriedade intelectual (CARCANHOLO, 1998).

Segundo Harvey (2008), "a dinâmica da neoliberalização tem agido de modo a forçar adaptações que variam muito de lugar para lugar e de época para época" (Idem., 2008, p. 80), podendo ser apontado aqui as seguintes versões: uma ortodoxa; outra que vem sendo chamada de "progressista", mas que conserva seus princípios ele- 
mentares $^{1}$, como o social-liberalismo ${ }^{2}$; e uma vertente denominada de ultraneoliberal ${ }^{3}$. Porém, Harvey (2008) esboçou alguns fios gerais de argumentação considerando dois campos em particular: o primeiro está relacionado à necessidade de forjar um clima de negócios ou de investimento favorável para os empreendimentos capitalistas; e o segundo diz respeito à necessidade do Estado de garantir a integralidade do sistema financeiro, a solvência das instituições que compõem esse sistema e a não proteção social da população e/ou do meio ambiente.

No Brasil, a neoliberalização desde os anos 1990 vem se expressando por meio de um movimento caracterizado pela formação de governos neoliberais ortodoxos, seguidos de governos que adotaram a versão social-liberal, mas que preserva os princípios econômicos e morais do neoliberalismo, e pelo retorno e o fortalecimento de uma vertente ortodoxa ou ultraneoliberal, com o início de governos de extrema direita, que demonstram não haver mais espaço para conciliação de classes. Nessa direção, Antunes (2018, p. 267)

[...] apontou que no país "o neoliberalismo vem se efetivando por meio de um movimento pendular, quer via governos neoliberais 'puros', quer pela ação de governos mais próximos ao social-liberalismo, sendo em ambos os casos os pressupostos fundamentais do neoliberalismo se mantêm essencialmente preservados".

Sendo assim, este capítulo, busca, em um primeiro momento, apresentar alguns traços da dinâmica da neoliberalização no Brasil, a

\footnotetext{
${ }^{1}$ Segundo Fraser, os "movimentos, que crescem em quase todo país do histórico centro do capitalismo, representam a resposta previsível ao 'neoliberalismo progressista' hegemônico do tempo presente, o qual cinicamente lança mão de apelos à "justiça" enquanto amplia a expropriação e corta o apoio público à reprodução social" (FRASER; JAEGGI, 2020, p. 12).

${ }^{2}$ De acordo com Castelo (2013, p. 121), "o social-liberalismo surgiu nos centros imperialistas em resposta à crise conjuntural vivenciada pelo capitalismo em meados dos anos 1990, com as crises financeiras nos países dependentes (México, Tigres Asiáticos, Rússia, Brasil, Argentina) e o tímido fortalecimento das forças políticas de contestação da ordem, como os ativistas do Fórum Mundial e o Exército Zapatista".

${ }^{3}$ Sobre a ascensão do ultaneoliberalismo após a crise de 2008 e com a vitória de candidatos da extrema direita a chefes de Estado, como EUA e Brasil, ver Cislaghi (2020).
} 
partir de uma análise dos governos nacionais desde o começo dos anos 1990.

Particularmente, sem desprezar as resistências de setores democrático-populares, procura demonstrar, que o neoliberalismo, com suas nuances estruturais e conjunturais, vem impondo limites às conquistas democráticas da classe trabalhadora, ao garantir os interesses do capital de dominação financeira por meio de distintos mecanismos construídos no âmbito do Estado, como: planos de estabilização da economia; medidas de ajuste fiscal permanente ${ }^{4}$ fundos de estabilização fiscal, hoje chamado de Desvinculação das Receitas da União, Lei de Responsabilidade Fiscal, congelamento de gastos sociais por vinte anos etc.);ampliação regressiva da carga tributária; privatização de empresas e serviços públicos; programas sociais de alívio ou "combate" à pobreza absoluta; portarias e leis que criminalizam os movimentos sociais e a pobreza; e realização de contrarreformas trabalhista, previdenciária e da administração pública, isto é, de uma verdadeira "contrarreforma do Estado, que [vem implicando num] profundo retrocesso social, em benefícios de poucos" (BEHRING, 2003, p. 22) ${ }^{5}$.

Em seguida, este capítulo busca demonstrar as consequências da ofensiva (ultra) neoliberal nas políticas de seguridade social (saúde, previdência e assistência social) no país, considerando os projetos em disputa nesse sistema de proteção social incorporado na Constituição Federal de 1988 a partir das reivindicações de setores democrático-populares. O destaque é dado ao contexto atual marcado pela ascensão de governos nacionais de extrema direita, que vêm im-

\footnotetext{
${ }^{4}$ Segundo Behring (2017, p. 10), “o Brasil convive há algumas décadas com uma espécie de ajuste fiscal permanente", que tem sido imposto sob o discurso de combater um suposto déficit fiscal, quando na verdade busca contribuir com a apropriação privada do fundo públi co pelo capital de dominação financeira.

${ }^{5}$ De acordo com Coutinho, o termo reforma esteve sempre relacionado às lutas das classes subalternas para transformar a sociedade. No entanto, o neoliberalismo busca utilizá-lo a seu favor; "as medidas por ele propostas e implementadas são mistificatoriamente apresen tadas como 'reformas'" (2008, p. 100), mas significam contrarreformas. Completou o autor: "é por isso que me parece mais adequado, para uma descrição dos traços essenciais da época contemporânea, utilizar não o conceito de revolução passiva, mas sim o de contrarreforma" (Ibid., p. 101).
} 
pondo um projeto de sociedade que conjuga ultraneoliberalismo com neofascismo.

\section{Os governos (ultra) neoliberais no Brasil}

\section{A Constituição Federal de 1988 atribuiu}

[...] prioridade quase exclusiva ao que é essencial para o grande capital nacional e, principalmente, para as multinacionais e a rede internacional de poder financeiro e político, que esmagam as potencialidades de desenvolvimento relativamente independente e equilibrado do país (FERNANDES, 2006, p. 74).

É claro que incorporou algumas reivindicações da classe trabalhadora, como os direitos sociais e políticos. Entretanto, se a Carta Constitucional inovou nessa direção, era "preciso inovar também em outra direção, que confira aos trabalhadores o aumento crescente dos meios coletivos de autodefesa e de luta política ofensiva" (Idem., 2006, p. 75), pois já se observava que as forças conservadoras lideradas pelo presidente Sarney (1985-1990) não conduziam as mudanças político-institucionais em consonância com os preceitos constitucionais.

De fato, Fernando Collor de Melo, após vencer a eleição direta para a presidência da República no ano de 1989, apresentou, em março de 1990, no Congresso Nacional as propostas do seu projeto de reconstrução nacional, que em muito se assemelhavam às medidas do receituário neoliberal (estabilização financeira que dependeria de uma ampla "reforma" conservadora que reduzisse os gastos públicos, o tamanho do aparelho estatal e incentivasse a economia de mercado). Segundo Antunes (2005), o neoliberalismo no Brasil iniciou-se com o governo desse presidente, que elaborou esse projeto nacional de integração subordinada ao capitalismo mundial. Tal projeto expressou-se por meio dos Planos Collor 1 e 2, que fracassaram antes mesmo do governo completar o seu primeiro ano.

O Plano Collor 1, todos lembramos, objetivava, através da recessão violenta, do arrocho salarial, do enxugamento da liqui- 
dez, da redução do déficit público, da privatização do Estado, estancar o processo inflacionário para abrir caminho para um real segundo momento, mais ofensivo, do Plano. É falso, portanto, quando se diz que o Plano Collor 2 é a continuidade natural do plano anterior. Não é. O Plano Collor 2 é o reconhecimento da falência das medidas imediatas e contingenciais do Plano Collor 1 [...]. O Plano Collor 2 é a tentativa, um bocado desesperada, de arrumar o país do estrago feito pelo plano anterior. Com o mesmo remédio, como se pode exemplificar: congelamento de preços e salários. Já se sabe, à exaustão, o resultado disto (ANTUNES, 2005, p. 13).

Além de abrir espaços para a incorporação do ideário neoliberal difundido no mundo capitalista, o governo Collor (1990-1992) também deu continuidade à forma tradicional de se fazer política no país. Segundo Fernandes (1990), este presidente alimentou a perpetuação do

[...] mandonismo, do paternalismo, do clientelismo e de todas as suas sequelas e condições, como a miséria, a cultura da ignorância para os de baixo e a opressão das classes subalternas, condenadas à privação da cidadania e à submissão passiva" (Idem.,1990, p. 33).

Entretanto, o descontentamento de frações da classe dominante e de setores democrático-populares com a crise econômica que se alastrava desde 1974; com as constantes denúncias de corrupção; e a má administração do governo Collor, levaram o Congresso Nacional a abrir uma Comissão Parlamentar de Inquérito, que resultou no seu impeachment em setembro de 1992. Segundo Antunes (2005), o processo de impeachment só foi concluído quando, além da pressão do movimento popular, o vice-presidente Itamar Franco, pressionado por setores dominantes, aceitou assumir a direção do país. Ou seja, por meio também de uma conciliação pelo alto que tem sido a marca da política brasileira. Seu governo (1992-1994) herdou uma crise estrutural de dimensões econômicas, sociais, políticas e éticas, como também foi marcado por profundas ambiguidades. 
Itamar praticou, sobre pretexto da interinidade, aquela ambiguidade que o caracterizou desde o início de seu governo: quanto mais fala no "social", na "miséria e sofrimento de miIhões de compatriotas", conforme a peça final do discurso em que anunciou seu plano econômico, mais implementa um projeto com traços de continuidade do Projeto Collor; critica a fome e concede mais de um bilhão de dólares aos usineiros; fala em um projeto autônomo e independente, mas dá continuidade às privatizações escandalosas, como a da Companhia Siderúrgica Nacional (CSN); chama Luiza Erundina para um ministério fraco e recruta Eliseu Resende para o Ministério da Fazenda; em vez de um imposto para o capital financeiro, tributa o assalariado que recebe pelos bancos (ANTUNES, 2005, p. 2122).

A maior preocupação do governo Itamar foi a de implantar o Plano Real, que seguiu o programa de estabilização proposto pelo FMI e as reformas recomendadas pelo Banco Mundial. Como parte deste Plano, o governo criou, ainda em 1994, o Fundo Social de Emergência - FSE (Emenda Constitucional - EC de Revisão no 1, de 01/03/1994), com o objetivo de promover o saneamento financeiro da Fazenda Pública Federal e contribuir com a estabilização econômica. Na condução deste Plano estava o ministro da Fazenda, Fernando Henrique Cardoso (FHC), que participou como candidato da eleição para a presidência da República em 1994. Ao sair vitorioso desse pleito pelo Partido da Social Democracia Brasileira (PSDB), FHC, no seu primeiro governo (1995-1998), tratou de renovar a tradicional coalizão entre as facções da burguesia brasileira dependente e associada às classes dominantes e suas frações no cenário mundial. Desse modo, procurou consolidar o projeto neoliberal, que atendia esse pacto de dominação e inviabilizava as conquistas dos setores democrático-populares que foram incorporadas na Constituição Federal de 1988.

FHC rapidamente deu efetividade ao projeto político do grande capital: sua base parlamentar, articulada fisiologicamente e reunindo as velhas e novas oligarquias, garantiu-lhe precisamente a inviabilização do projeto social contido na Constitui- 
ção de 1988 [...] em dois planos: no plano jurídico, dando forma a uma reforma/revisão constitucional que acabou por retirar da Carta elementos fundamentais (neste sentido, a "reforma da previdência" é emblemática); e, substantivamente, no plano prático-concreto, dando curso a um "modelo de desenvolvimento" (NETTO, 1999, p. 79).

No plano prático-concreto, esse projeto neoliberal se expressou logo no início do governo FHC com a publicação da Medida Provisória (MP) no 813, em 01/01/1995 -, que extinguiu os principais órgãos e instituições sociais, criou ministérios e programas sociais que, por contarem com recursos financeiros do Banco Mundial, passaram a seguir as suas diretrizes -; com a imposição da contrarreforma do Estado, particularmente da administração pública e da previdência social; com a privatização das empresas de energia elétrica, de telecomunicações e da Vale do Rio Doce; com a renovação em 1996 do FSE, denominado agora de Fundo de Estabilização Fiscal e nos anos 2000 de Desvinculação das Receitas da União (DRU), que passou a retirar, a cada ano, $20 \%$ dos recursos dos fundos públicos, incluídos os destinados à seguridade social, para honrar com o pagamento de juros e encargos da dívida pública; e com a instituição, ainda no ano de 2000, da Lei de Responsabilidade Fiscal (LRF), que passou permitir que os governos, em nome da austeridade, cortem gastos, como os da área social, exceto os relacionados à dívida pública.

Contudo, entre o final do primeiro mandato e o segundo governo FHC (1999-2002), os reflexos da crise estrutural do capital em diferentes regiões e países expuseram as fragilidades da economia nacional associada e dependente. Mantendo a mesma política econômica neoliberal, que incentivava a reestruturação produtiva comandada pela financeirização, o governo foi perdendo popularidade conquistada com a estabilização da economia advinda do Plano Real, mas que produziu um elevado custo social, na medida em que reduziu o mercado formal de trabalho, sobretudo no setor da indústria, precarizou as condições e relações de trabalho e atacou os direitos sociais conquistados na Constituição Federal de 1988.

A vitória de Luiz Inácio Lula da Silva, em 2002, na eleição para presidência da República, pelo Partido dos Trabalhadores (PT), ex- 
pressou o descontentamento dos trabalhadores e de uma fração da burguesia nacional com a política econômica implementada pelo FHC; e a perda de referência política e ideológica de alguns setores da esquerda no país, particularmente de dirigentes do PT, em decorrência das transformações que ocorriam no mundo e no Brasil. A aliança com os setores capitalistas nacionais representados pelo empresário têxtil, José Alencar, candidato a vice-presidente da chapa composta por Lula, foi a principal explicitação das transformações política e ideológica desse partido durante a campanha para presidência da República. Destaca-se também nesse período eleitoral, a realização pelo PT de um encontro e a divulgação da "Carta ao Povo Brasileiro", assinada pelo Lula, na qual demonstrava uma explicita aliança ao empresariado, às instituições do capital financeiro (os organismos multilaterais), às grandes empresas e às potências imperialistas. Por meio dela, o governo Lula estabelecia o compromisso de não romper os contratos afirmados pelo governo FHC.

Ainda que seja por meio de uma variante social-liberal, o governo Lula, nos seus dois mandatos (2003-2010), manteve a política econômica do governo anterior, reeditou a LRF, adotou a DRU (que manteve percentual de $20 \%$ desvinculação), realizou a contrarreforma da previdência e a tributária de acordo com as orientações do Banco Mundial. Para manter uma política econômica voltada aos interesses do capital financeiro e realizar essas medidas contrarreformistas, o governo criou estratégias intergovernamentais, cooptou instituições e organizações políticas que entre os anos 1970 e 1980 dedicaram-se a construir uma contra-hegemonia, como sindicatos, a Central Única dos Trabalhadores (CUT), o próprio PT, que assumiram cargos de direção nos conselhos dos fundos de pensão, em empresas estatais, órgãos federais etc. Assim, o governo Lula desmobilizou setores da classe trabalhadora e parte expressiva dos movimentos sociais com a renovação do corporativismo e do patrimonialismo, que se aliavam a estratégia do governo de cooptação. Portanto, "a chegada do PT ao governo federal em 2003, longe de contribuir para minar a hegemonia neoliberal, como muitos esperavam, reforçou-a de modo significativo"(COUTINHO, 2008, p. 141). 
O governo de Dilma Rousseff (2011-2016), também eleita pelo PT, seguiu as mesmas diretrizes do seu antecessor. Durante os treze anos desses governos nacionais do PT, que aderiram ao neoliberalismo por meio do social-liberalismo, notou-se que, embora tenham implementado políticas de ajuste em consonância com as medidas do Consenso de Washington, também investiram em políticas e programas sociais destinados ao enfrentamento da pobreza absoluta, sem, contudo, alterar os índices alarmantes de desigualdade e confrontar com os interesses do capital, sobretudo de dominação financeira. Porém, a liberalização dos fluxos comerciais e financeiros mantida como parte das políticas de ajuste, ao promover a integração do país de forma subalterna ao mercado mundial, deixou o país suscetível às ocorrências internacionais. Assim, a crise de dimensões estruturais e conjunturais, que não foi suplantada desde 2008 (com a crise na Grécia) e que voltou a dar seus sinais nos Estados Unidos e na Europa, alteraram a situação econômica, política e social do Brasil.

A partir desse momento, aprofundou-se o descontentamento de diversos setores da sociedade com o governo Dilma. As manifestações que ocorreram em junho de 2013 são exemplos desse descontentamento social. Em resposta, o governo ampliou as portarias e leis que intensificam a criminalização dos movimentos sociais; cresceu a ação truculenta da polícia militar contra os manifestantes que se situam à esquerda no espectro político; e aumentou o apoio (sobretudo do judiciário e da grande mídia) da atuação da direita que, com a defesa de valores conservadores e neofascistas, tem convocado e liderado, como nunca antes visto na história do país, manifestações nas ruas, que foram a favor do impeachment da presidente Dilma e que tiveram e tem como pretexto o combate à corrupção, a alta carga tributária etc.

A aprovação do pedido de admissibilidade do processo contra essa presidente na Câmara dos Deputados em 17 de abril de 2016 e no Senado entre os dias 25 e 31 de agosto, sem a devida comprovação de crime de responsabilidade fiscal, configurou-se como um golpe travestido de legalidade, que também contou com o aval do Supremo Tribunal Federal, de setores do Judiciário, da Polícia Federal e 
da grande mídia. Assim, foi aprovado pelo Senado Federal no dia 31 de agosto de 2016 o impeachment dessa presidente.

Com sua deposição e a posse do seu vice, Michel Temer (que também participou dos esquemas que deslocaram a base de apoio do governo) iniciou-se um "novo" período da história do país marcado pelo aumento do conservadorismo, do neofascismo e pela ofensiva ultraneoliberal, que de forma rápida, agressiva e radical vem buscando, como forma de atender os interesses do capital de dominação financeira, privatizar empresas e serviços públicos; e desconstruir os direitos sociais que ainda restam. Dentre as medidas ultraneoliberais do governo ilegítimo de Temer (2016-2018) destacam-se: a aprovação da EC 93/2016 (construída no governo Dilma), que prorrogou a DRU até 2023 e aumentou seu percentual de $20 \%$ para $30 \%$; a aprovação da EC no 95, de 2016 (conhecida também como PEC do Teto dos Gastos Públicos), que instituiu um "novo" ajuste fiscal e que estabeleceu um limite/teto para as despesas primárias por um período de 20 anos; a Lei da Terceirização, no 13.429/31 de março de 2017, que regulamenta a prática e permite que as empresas terceirizem até mesmo as atividades-fim; a contrarreforma trabalhista (Lei 13.467, de julho de2017) e criação do projeto de contrarreforma da previdência social.

Desde a campanha para eleição da presidência da República em 2018, as propostas do candidato Bolsonaro eleito pelo Partido Social Liberal (PSL), hoje sem partido, já demonstravam que seu governo daria continuidade a implementação dessas medidas ultraneoliberais, como também criaria outras. A vitória desse candidato nesse pleito está associada à crise internacional do capital e seus efeitos na economia brasileira, ao fracasso dos governos de conciliação de classes, à falta de estabilidade do governo ilegítimo que seguiu ao golpe institucional, à dificuldade da direita golpista de encontrar uma alternativa eleitoral viável, à desarticulação política do PT, ao movimento de caráter neofascista que se desenvolve mundialmente nesse contexto de crise e que acabou por fortalecer a extrema direita no país. Essa alternativa reacionária e ultraneoliberal deslocou no período eleitoral a responsabilidade pela crise e suas consequências para os 
seus adversários, com a utilização de propagandas falsas, que se assemelham aos instrumentos do fascismo (IASI, 2018).

Para compor o seu governo, Fontes (2019, n.p) apontou que "os ministérios foram implantados de maneira hierárquica e autocrática, sob a autoridade direta de Bolsonaro e influência de alguns personagens próximos a ele (e filhos)". Particularmente, o ministério da Economia, Fazenda, Planejamento, Indústria e Comércio Exterior foi assumido pelo empresário Paulo Guedes, com formação acadêmica na Escola de Chicago: conhecida mundialmente por ser uma das escolas de um dos principais expoentes do neoliberalismo, Milton Friedman. Guedes e sua equipe econômica ultraneoliberal vêm propondo um programa que favorece o mercado, principalmente o financeiro. Como parte desse programa, destaca-se a contrarreforma da previdência social aprovada por meio da Proposta de Emenda à Constituição $n^{\circ}$ 6, de 2019 (PEC 6/2019); o Plano Mais Brasil, constituído pela PEC Emergencial, PEC dos Fundos, PEC do Pacto Federativo; e o projeto de contrarreforma da administração pública.

Porém, com a pandemia da Corona Virus Disease iniciada no mundo em 2019 (COVID-19), que vem agravando a crise do capital e expondo a olho nu a forma pela qual o capitalismo vem explorando a força de trabalho, a tramitação do Plano Mais Brasil, que havia sido encaminhado em novembro de 2019, foi interrompida. Nesse período, o Banco Central divulgou um pacote de medidas que liberou para os bancos um valor dez vezes maior do que foi investido durante a crise de 2008, isto é, cerca de $\mathrm{R} \$ 1,2$ trilhão para atenuar os possíveis efeitos provocados pela pandemia do novo Coronavírus. A consequência disso é o agravamento da precarização social do trabalho, na medida em que a reestruturação produtiva tem sido comandada pelo capital de dominação financeira (DRUCK, 2011).Porém, o governo não usou dessa mesma agilidade, como também não disponibilizou um montante de recursos financeiros como esse, para fortalecer as políticas sociais nesse contexto de pandemia, que agravou ainda mais o desemprego, aumentou a informalidade, os problemas de saúde, as diversas formas de violência intrafamiliar e social etc.

Embora o Congresso Nacional represente muito mais os interesses da classe dominante e de suas frações, a iniciativa veio do pre- 
sidente da Câmera dos Deputados que construiu a PEC 10/2020. Depois de idas e vindas entre as duas casas do Congresso, essa PEC do Orçamento de Guerra, como ficou conhecida, foi aprovada e instituiu um regime extraordinário fiscal, financeiro e de contratações para enfrentar à calamidade pública no país decorrente da pandemia. Por meio dessa medida, o governo Bolsonaro não precisa cumprir a LRF e a Regra de Ouro. No entanto, sua aprovação não significou um investimento robusto, em longo prazo, para enfrentar a pandemia e fortalecer as políticas sociais. Pelo contrário, o seu caráter emergencial indica que o governo segue com sua agenda ultraneoliberal.

A proposta desse governo de criação de um auxílio emergencial no valor ínfimo de $\mathrm{R} \$ 200,00$, nesse contexto da pandemia em que miIhões de trabalhadores e famílias estão sem emprego, trabalho e não tem acesso a nenhum beneficio assistencial ou previdenciário, demonstra o seu total descaso com as necessidades sociais da classe trabalhadora. No Congresso, essa proposta foi rejeitada pela oposição, que aprovou a Lei no 13.982, de 2/04/2020, que também prevê durante o período de 3 meses, a contar da publicação da Lei, um auxílio emergencial no valor de $\mathrm{R} \$ 600,00$ mensais aos trabalhadores informais, aos chamados microempreendedores individuais, autônomos e desempregados. O Decreto $\mathrm{n}$ - 10.412, de 30/06/2020 prorrogou esse auxílio emergencial pelo período complementar de dois meses, mas que vem sendo marcado pela burocratização do seu acesso.

Nota-se assim que parlamentares, como também chefes do Executivo, vêm se utilizando da pandemia para propor, implantar e/ ou acelerar medidas que afetam a classe trabalhadora, sobretudo os setores mais pauperizados. Destaca-se no âmbito das relações de trabalho, as MPs de no 927, 928e 936, que flexibilizam, ainda mais, as relações trabalhistas; delegam aos empregadores um conjunto de prerrogativas e poderes, que restringem a atuação do alcance dos sindicatos, principalmente por estabelecerem acordos individuais; e que atacam assim os direitos trabalhistas. Além dessas medidas, o governo Bolsonaro encaminhou, recentemente, o projeto de contrarreforma administrativa (PEC 32/2020), que procura alterar a forma de contratação de servidores, o número de carreiras, a remuneração e outros aspectos da administração pública, que podem acelerar a destruição 
do serviço público, principalmente no âmbito das políticas sociais, em especial aqui da seguridade social.

\section{A ofensiva (ultra) neoliberal na seguridade social}

Desde os anos 1990, apesar das resistências dos sujeitos progressistas, medidas recessivas e contrarreformistas têm sido formuladas e adotadas pelos governos (ultra) neoliberais e atingem de forma trágica a seguridade social, o seu caráter público, universal, democrático e descentralizado, fundamental para a garantia dos direitos à saúde, previdência e assistência social, como também impedem a construção e incorporação de novos direitos sociais. Nota-se, dessa maneira, que no âmbito desse padrão de proteção social, ainda inconcluso, a disputa de projetos que estão sendo fundamentados por dois modelos ou projetos de sociedade. De acordo com Coutinho (2008):

Por um lado, há um modelo que poderíamos chamar de "norte-americano" [ou liberal-corporativo], caracterizado (como ocorre em toda situação "ocidental") pela presença de uma sociedade civil forte, bastante desenvolvida e articulada, mas onde a organização política e a representação dos interesses se dá, respectivamente, por meio de partidos frouxos, não programáticos, e através de agrupamentos profissionais estritamente corporativos. E, por outro, temos um modelo que poderíamos designar como "europeu" [ou democracia de massa]. Neste último, há uma estrutura partidária centrada em torno de partidos com base social razoavelmente homogênea e que defendem projetos de sociedade definidos e diversos entre si; e temos um sindicalismo classista, que não se limita a organizar pequenos grupos profissionais, mas que busca agregar e representar o conjunto da classe trabalhadora (Idem.,2008, p.134).

Na Carta de Maceió publicada pelo conjunto CFESS-CRESS (2000, p. 1-2), essa proteção social é compreendida como "um espaço de disputa de recursos - uma disputa política que expressa projetos societários [...]. O resultado desse embate tem forte impacto so- 
bre uma parcela enorme da população que conta com as políticas de seguridade para sua sobrevivência". Não só o processo de formulação, como também o da implementação das políticas de seguridade social, possuem divergências quanto às concepções teóricas, aos objetivos, ao financiamento e às formas de dar respostas às expressões da "questão social", tendo em vista a participação de distintos sujeitos, com interesses diferenciados vinculados aos projetos societários em disputa.

Segundo lamamoto (2009), evidencia-se uma proposta que se orienta pelos princípios da seguridade social e dessa maneira aposta: na democratização, com base na participação popular e no controle social democrático; na universalização dos direitos sociais (da cobertura e dos atendimentos); na primazia do Estado; no respeito ao pacto federativo; na descentralização do poder; na defesa da gratuidade no acesso aos serviços sociais; e na integralidade das ações dirigidas à defesa da cidadania. Entretanto, essa proposta político-institucional tem sido tensionada por uma proposta neoliberal, que segue as políticas de ajuste recomendadas pelos organismos multilaterais e que busca o descolamento das ações públicas para a esfera privada. Tal proposta neoliberal é representada pelo capital (inter) nacional e a político-institucional/democrática pelos trabalhadores, que tencionam a seguridade social e imprimem a esse sistema de proteção social as marcas de uma unidade contraditória. Dada à hegemonia do projeto conservador a partir dos anos 1990, constata-se um movimento de resistência e defesa da seguridade social, que critica e procura criar formas para impedir a privatização, a mercantilização das políticas de saúde e previdência; e o processo de assistencialização da proteção social. Esse movimento tem sido impulsionado pelas forças sociais norteadas por duas posições básicas:

[...] a preservação da concepção de seguridade social conforme postulada na Constituição de 1988 [...]. Essa posição alinha-se com as propostas dos trabalhadores [...].b. o desmantelamento da seguridade social pública, por meio da separação das políticas de previdência, saúde e assistência, que passam a ser agenciadas pelo mercado, reguladas pelo Estado e tornadas objeto do consumo mercantil de parte dos trabalhadores assalariados 
e de assistência para os pobres. Ancoradas nessa posição estão os representantes do grande capital (MOTA, 2000, p. 192).

Nessa direção, Behring e Boschetti (2006) apontam no atual padrão de proteção social uma difícil coexistência entre inovação e conservadorismo e/ou entre universalização e hegemonia neoliberal, tendo em vista que apesar das forças progressistas lutarem pela realização de reformas democráticas, muitas contra tendências se opõem a essa possibilidade. Assim, assiste-se, não sem resistência, uma contrarreforma do Estado, que obstaculiza e/ou redireciona as conquistas incorporadas na Constituição Federal de 1988 e nas leis orgânicas das políticas de seguridade social.

Particularmente, no âmbito da política de saúde constatam-se formas diferenciadas de conceber e de gerir essa política social, que são orientadas pelos projetos societários em disputa: o liberal-corporativo e o democracia de massas (COUTINHO, 1992), ou o democracia restrita e o democracia de massas (NETTO, 1990) (BRAVO, 2001), que fundamentam os projetos distintos nessa área que convivem em tensão, a saber: o projeto de reforma sanitária, que começou a ser construído nos anos 1980 e que conseguiu incorporar suas propostas na Carta Constitucional de 1988; e o projeto privatista, que se tornou hegemônico desde a segunda metade da década de 1990. O projeto de reforma sanitária defende a construção do Sistema Único de Saúde (SUS) público, universal e de qualidade; e conta com a participação de sujeitos coletivos progressistas, como profissionais dessa área que são representados por suas entidades; partidos políticos de esquerda; frente popular; movimentos sociais, entre eles: o Movimento Sanitário, que tem o Centro Brasileiro de Estudo de Saúde/CEBES como um dos canais político-institucionais de difusão e defesa de suas propostas (BRAVO, 2001).

Por sua vez, o projeto privatista tem sido representado e defendido pelos sujeitos reformistas, como os empresários do setor hospitalar, da indústria farmacêutica, os organismos internacionais, os partidos políticos de direita, os profissionais e gestores conservadores. Esse projeto, desde os governos neoliberais de FHC, vem contribuindo com a mercantilização e a privatização dos serviços de saúde, nesse último caso por meio de determinadas organizações e insti- 
tuições da sociedade civil (como as Organizações Sociais - OSs, Organizações da Sociedade Civil de Interesse Público - OSCIPs, Fundações de direito privado e a Empresa Brasileira de Serviços Hospitalares EBSERH), como também procura manter ações mínimas para os trabalhadores que não têm condições financeiras de consumir tais serviços.

Nos governos nacionais do PT, Bravo (2006) apontou que os dois projetos existentes na saúde continuaram em disputa. Entretanto, constatou que alguns sujeitos defensores do projeto de reforma sanitária, sobretudo aqueles que assumiram cargos de direção em órgãos do governo, flexibilizaram suas proposições, considerando as possibilidades da atuação do Estado influenciado pela vertente social-liberal do neoliberalismo. Assim, se perdeu de vista a perspectiva da reforma sanitária relacionada às lutas mais gerais das classes trabalhadoras e à transformação da sociedade. Em razão do transformismo nessa área social, Bravo e Menezes (2008, p. 21) alertam que os defensores da

[...] reforma sanitária e do projeto 'democracia de massas' só conseguirão contribuir para reverter às profundas desigualdades existentes na atual conjuntura brasileira aliando-se a um amplo movimento de massas.

A criação da Frente Nacional Contra a Privatização da Saúde em 2010, que articula fóruns interestaduais e que defende um SUS público, estatal e de qualidade, tem atuado nessa direção, pois recupera os princípios originais da reforma sanitária, a partir de uma perspectiva mais ampla da saúde, que considera as determinações sociais do processo saúde-doença e que articula essa política social a um projeto de transformação da sociedade. Exatamente por isso, essa Frente tem participado das manifestações contrárias às contrarreformas trabalhista, previdenciária e a outras medidas que retiram direitos.

No governo ilegítimo de Temer, notou-se uma aceleração das medidas contrarreformistas no âmbito da política de saúde decorrentes do seu projeto ultraneoliberal. Destaca-se o congelamento de recursos orçamentários para as políticas sociais por vinte anos, aqui em 
especial para política de saúde; a manutenção do processo de privatização não clássico, ou seja, que ocorre por dentro dessa política social; a proposta de um Plano de Saúde Acessível; de mudanças na Política Nacional de Atenção Básica (PNAB), que restringe o acesso à assistência aos segmentos da população considerados mais "vulneráveis" e que se limita, assim, a ofertar serviços de saúde muito aquém das necessidades básicas dos usuários; as alterações na política de saúde mental, que se configuram como ameaças às conquistas da Reforma Psiquiátrica, na medida em que o governo -, por meio da Portaria 3.588/, de 21/12/2017 que dispõe sobre a Rede de Atenção Psicossocial -, procura incentivar as internações em hospitais psiquiátricos, como também cria leitos em hospitais gerais e serviços ambulatoriais destinados a pacientes da saúde mental; e a sua articulação com o setor privado através da Coalizão Saúde Brasil, que busca construir um novo sistema de saúde para o país (BRAVO et al., 2018).

Apesar da luta dos setores democrático-populares contra o desmonte do SUS, o governo Bolsonaro, sob o discurso gerencialista de tornar o Programa Mais Médico "mais técnico e menos político", propôs a criação do Programa Médicos pelo Brasil, que acabou destruindo o Programa anterior. Assim, esse governo conseguiu reduzir os servidos médicos nas regiões e localidades mais atrasadas, e que historicamente não vêm conseguindo reter esses profissionais. Por meio da Lei no 13.958, de 18/12/2019, que instituiu o novo Programa, o governo também autorizou a criação da Agência para o Desenvolvimento da Atenção Primária à Saúde (ADAPS), que aprofunda a terceirização de profissionais e da gestão de serviços de saúde em escala nacional.

Através da criação da Nota Técnica no 11/2019, da Coordenação Geral de Saúde Mental, Álcool e outras Drogas, o governo vem reduzindo, por um lado, a atuação dos Centros de Atenção Psicossocial (CAPS); e, por outro lado, vem fortalecendo as chamadas "comunidades terapêuticas", que são ineficientes nessa forma de atenção, principalmente por se configurarem, em termos práticos, como espaços de violações de direitos. A referida Nota Técnica no 11/2019 também libera a compra de aparelhos de choque elétrico e fortalece os manicômios; desse modo, desconsidera também as conquistas da re- 
forma psiquiátrica e a luta antimanicomial que existe há décadas no país.

Somado a essas mudanças, o Ministério da Saúde criou, dentro da sua estrutura, o Departamento de Saúde Digital, que busca incentivar a teleconsultoria, a telediagnóstico e a tele-educação; o Departamento de Certificação e Articulação com Hospitais Filantrópicos e Privados, que estabelece contratualização com o setor privado; e a reestruturado do Departamento de Infecções Sexualmente Transmissíveis (IST), Aids e Hepatites Virais, que passou a ser denominado de Departamento de Doenças de Condições Crônicas e Infeç̧ões Sexualmente Transmissíveis. Esse Departamento passou a incluir o departamento doenças como hanseníase e tuberculose. Desde então, essa junção vem recebendo críticas de entidades ligadas à luta no âmbito das ISTs, que temem retrocessos ou perda de espaço das ações contra o HIV/Aids, que são referências no Brasil e no mundo (BRAVO et al.,2020).

A pandemia da COVID-19 demonstrou o desmonte que o SUS vem passando há décadas, ao mesmo tempo em que revelou sua importância para enfrentar essa crise sanitária. No entanto, o governo Bolsonaro vem acelerando esse desmonte com a troca de ministros motivada por questões pessoais e políticas; a promoção de um general para o Ministério da Saúde e de uma equipe de militares sem qualquer experiência técnica na área da saúde; o diagnóstico sobre a pandemia como sendo uma "gripezinha" e a recomendação do uso de medicamentos que não tem comprovação científica (uma grande parte doada pelos Estados Unidos); a extinção de serviços de saúde mental para presidiários com transtornos mentais; a exoneração de técnicos do Ministério da Saúde, que assinaram uma nota técnica sobre a saúde sexual e reprodutiva, alertando sobre a importância das mulheres não interromperem seus tratamentos durante a pandemia; o apagão na base de dados dessa pasta sobre a incidência da COVID-19, o incentivo a invasão dos hospitais por parte dos seus apoiadores para verificarem, supostamente, a existência de leitos vagos (FLEURY, 2020) e a incitação de outras formas de violência, que precarizam não só o SUS, mas as condições de vida e de saúde da classe trabalhadora. 
Na política de previdência social, a ofensiva (ultra) neoliberal, apesar das resistências de setores democrático-populares, também vem promovendo uma contrarreforma permanente nessa área desde os anos 1990. De acordo com Teixeira (2006), nota-se também no âmbito dessa política social há expressão da disputa entre o projeto "liberal-corporativo" e o projeto de "democracia de massas", uma vez que essa autora menciona que, apesar de Coutinho (2008) não tratar dessa política social,

[...] é fácil deduzir que aquilo que ele chama de modelo 'americano' tende a transformar o mercado no gestor das questões previdenciárias, enquanto o modelo 'europeu' considera os direitos sociais como um dever do Estado (Idem., 2006, p. 95).

Segundo Teixeira (2006), a Constituição de 1988 pouco inovou em relação à previdência social. A principal inovação foi a inserção dessa política no âmbito da seguridade social, o que possibilita ultrapassar a sua compreensão restrita à lógica do seguro. Todavia, os limites estruturais e conjunturais impostos a esse sistema de proteção social mais universal e abrangente aprisionam a previdência à lógica contributiva. Além disso, desencadeiam um falso discurso políticoideológico sobre a "crise" nesse setor, que tem sido utilizada como um dos argumentos principais para realização da contrarreforma previdenciária. Nessa direção, identifica-se uma:

[...] intrínseca relação da "crise" da previdência pública como razão do crescimento da "previdência privada"; dito de outro modo: sustentaremos aqui que a lenta erosão da previdência pública é condição econômico-financeira e político-ideológica e também produto para/da construção da previdência complementar [como] uma mediação para a realização do capital portador de juros (GRANEMANN, 2006, p. 10).

Do governo FHC, passando pelos governos Lula, Dilma, do ilegítimo Temer e agora pelo governo Bolsonaro, nota-se que o pretexto para realizar a contrarreforma da previdência social é o suposto déficit das suas contas, que é constatado pelas instituições e analistas 
que visam beneficiar o mercado financeiro. Esses representantes do capital de dominação financeira vêm produzindo um diagnóstico das finanças da previdência, desvinculando essa política do conjunto da seguridade social, ou seja, desconsiderando todas as fontes de recursos e as despesas desse sistema de proteção social, como também os recursos que são desviados para outros fins, principalmente por meio da DRU. Além disso, consideram a contrarreforma como um prérequisito para o ajuste fiscal e a estabilização econômica.

De um modo geral, os projetos de contrarreforma da previdência social aprovados no governo FHC (EC - 20/2018), no governo Lula (EC - 40/2003; EC - 41/2003; EC - 77/2003, no governo Dilma (MP - 676/2015, que deu origem a Lei 13.183/2015; MP 676/2015) e nos governos seguintes, por meio de Emendas Constitucionais, Medidas Provisórias, mas também de decretos, vêm dificultando o acesso à proteção previdenciária, pois, em síntese, aumentam a idade para solicitar a aposentadoria, ampliam o número de contribuições, combinam contribuições por tempo de serviço e idade, determinam pisos e tetos, criam fórmulas ou alteram cálculos para aposentadoria, passam a exigir a cobrança de tributos a aposentados e pensionistas etc. Assim, buscam forçar que os trabalhadores venham a contribuir com planos de capitalização privados chamados de "previdência complementar".

Particularmente, no governo ilegítimo de Temer, o discurso a favor da PEC 287/2016 -, que ameaçou o direito à previdência social, sobretudo o direito à aposentadoria -, pautou-se também na suposta "crise" nesse setor, como forma de contribuir com o fortalecimento dos planos de capitalização privados. Entretanto, pesquisas/estudos mais sérios sobre o uso do fundo público, cuja forma mais visível é o orçamento estatal, como também algumas organizações políticas que defendem os interesses da maioria trabalhadora, têm demonstrado um elevado superávit da seguridade social; e apontado que a contrarreforma da previdência social intensifica a mercantilização dos serviços, com a ampliação da oferta de planos de previdência privada e fundos de pensão de natureza aberta, além de liberar mais recursos orçamentários para pagar os juros e amortizações da dívida. Neste governo, ocorreu a extinção do Ministério da Previdência Social. Com 
isso, o Instituto Nacional do Seguro Social (INSS) foi transferido para o novo Ministério do Desenvolvimento Social e Agrário; a Superintendência Nacional de Previdência Complementar (PREVIC) e da Empresa de Tecnologia e Informações da Previdência Social (DATAPREV) foram deslocadas para o Ministério da Fazenda: pasta que tem sido assumida desde os anos 1990 pelos representantes do capital de dominação financeiro e que está mais suscetível às pressões do mundo das finanças.

O presidente Bolsonaro antes mesmo de completar um ano de governo, encaminhou o projeto de contrarreforma da previdência social (PEC no 103/2019) ao Congresso Nacional, que depois de discussões e negociações, foi aprovado na Câmara e no Senado, atendendo principalmente os interesses do capital de dominação financeira, tendo em vista que, ao aumentar o tempo de trabalho e reduzir os benefícios, essa contrarreforma expropria os trabalhadores, sobretudo os mais pauperizados que compõem a massa de contribuintes, e ao mesmo tempo força os trabalhadores que ganham maiores salários a contribuírem com a chamada "previdência complementar".

Na política de assistência social, as vanguardas que compreendem essa e as demais políticas de seguridade social na dinâmica da reprodução ampliada do capitalismo contemporâneo de dominação financeira (RODRIGUES, 2016) têm denunciado que, nesse contexto marcado pela privatização e mercantilização da previdência e da saúde, o crescimento dos programas de renda mínima, sem a ampliação dos serviços socioassistenciais e o fortalecimento do sistema de seguridade social como um todo, só reforça a constituição de um padrão mínimo de proteção social, que não assegura direitos. De acordo com Silva (2014), a construção da assistência social como política pública também tem sido resultado das tensões entre projetos distintos nessa área social, alinhados a projetos antagônicos de sociedade: o liberal-corporativo e o de democracia de massas ou de democratização. Em decorrência da hegemonia do projeto neoliberal de assistência social que conserva aspectos de um projeto tradicional, e que colide e convive com um projeto que concebe a assistência como direito social e dever do Estado, vem sendo construído a partir da segunda me- 
tade da década de 1990 um padrão híbrido de gestão no âmbito dessa política social.

No governo de FHC, por meio da MP no 813, esse presidente da República extinguiu os principais órgãos e instituições de assistência social, criou o Ministério da Previdência e Assistência Social e, paralelamente, o Programa Comunidade Solidária. Assim, esta área foi concebida como um assunto que, na agenda do governo, não deveria exigir exclusivamente a elaboração de uma política pautada em princípios e diretrizes importantes para garantir o acesso a direitos sociais. Pelo contrário, continuava sendo vista como uma área que exige esforços da presidência da República e de outros órgãos comandados pelo primeiro-damismo para elaborar e implementar, em parceria e em solidariedade com a sociedade, um conjunto de ações focalizadas, sobrepostas e voltadas ao "combate" à pobreza absoluta.

No Programa de Governo 2002 Coligação Lula Presidente, esse candidato à presidência da República mencionou o desrespeito legal que o governo nacional da época promoveu com suas ações focalizadas, seletivas, desconectadas das políticas de seguridade social. Dessa maneira, para enfrentar o padrão vigente que promovia as relações clientelistas e assistencialistas, o seu programa de governo defendia a construção de um sistema descentralizado e participativo que tencionasse a política patrimonialista e efetiva-se a assistência como direito de cidadania sob o controle democrático. Porém, ao aderir o neoliberalismo pela via do social-liberalismo, o governo Lula e posteriormente Dilma, impuseram limites à Política Nacional de Assistência Social (PNAS) de 2004, ao Sistema Único de Assistência Social (SUAS) e à seguridade social, pois centralizaram as ações em programas e/ou planos direcionados ao enfrentamento da pobreza absoluta, como o Bolsa Família, o Plano Brasil sem Miséria e o Programa Brasil Carinhoso (esses dois últimos criados no governo Dilma), que transformaram o SUAS em um sistema de mínimo sociais, ao mesmo tempo em que demonstravam a concepção do governo da assistência social como política exclusiva de proteção social.

Contudo, com o golpe institucional que se expressou com o impeachment da presidente Dilma e a posse do seu vice, Temer, as medidas ultraneoliberais resgataram/reforçaram a seu favor o que 
existe de mais tradicional/conservador nessa área social. Desse modo, algumas conquistas possibilitadas com o advento da PNAS/ SUAS foram duramente atacadas, pois o governo ilegítimo de Temer reforçou a condição de ajuda da assistência social, por meio do congelamento dos recursos; da redução drástica do orçamento; do retorno do primeiro-damismo no governo nacional; da descoordenação das ações; do descumprimento do comando único e das medidas deliberadas na conferência nacional da área, dos critérios ainda mais rígidos de seleção e acompanhamento dos usuários; do aprofundamento da precarização das condições e relações de trabalho; do incentivo ao trabalho de visitadores sociais vinculados ao Programa Criança Feliz, de voluntários; da promoção da caridade e da filantropia etc.

O governo Bolsonaro vem aprofundando essas medidas ultraneoliberais que reforçam os traços mais tradicionais nessa área social. No final do primeiro ano desse governo, o Ministério da Cidadania publicou a Portaria no 2362/2019, que visa promover a equalização do cofinanciamento federal do SUAS à Lei de Diretriz Orçamentárias e à Lei Orçamentária Anual. Com essa medida, o governo desconsidera o pacto federativo previsto no âmbito do SUAS, estabelece critérios de adequação dos repasses dos recursos e da redução por meio dessa "equilização", que coloca em risco a existência desse Sistema em todo o país, principalmente nos municípios de pequeno porte (CONGEMA, 2020).

Esse governo-, apesar de ter cumprido a promessa que fez na campanha eleitoral de pagar o 130 do Programa Bolsa Família, ou seja, o pagamento do valor do auxílio financeiro em dobro aos beneficiários no final do ano -, propôs um orçamento anual do Programa para 2020 inferior ao de 2019 e sem a previsão do 13 para os beneficiários $^{6}$, o que demonstra não haver perspectiva para inclusão de novos beneficiários inscritos no Cadastro Único para Programas Sociais (CADÚNICO). Essa perspectiva também ocorre com o Benefício de Prestação Continuada (BPC), tendo em vista que, embora seja um direto assistencial voltado para idosos a partir de 65 anos e pessoas com

\footnotetext{
${ }^{6}$ Segundo a Folha de São Paulo (2019, n.p), "o projeto de Orçamento elaborado pela equipe econômica reservou $\mathrm{R} \$ 29,5$ bilhões para o programa no próximo ano -menos que os $\mathrm{R} \$ 32$ bilhões de 2019 e sem a previsão do 13 para beneficiários, prometido pelo presidente".
} 
deficiência, que tenham uma renda mensal de até um quarto do salário mínimo por pessoa, e que são incluídos como beneficiários desde que estejam dentro desse perfil -, nota-se uma morosidade no processo de liberação do benefício, a perda de validade de medidas importantes que garantiriam o 13 também aos beneficiários do BPC (como a MP 898/2019), e a crescente ameaça do governo para realizar cortes no valor e no número de beneficiários, que veio acompanhada, logo em seguida, da publicação pelo governo da Portaria Conjunta no $7 / 2020$. Essa Portaria regulamenta regras e procedimentos de requerimento, concessão, manutenção e revisão do BPC, demonstrando, segundo a Folha de São Paulo (2020), a sua intenção de economizar R\$10 milhões por ano. Além disso, a concepção de assistência como ajuda e não como direito que orienta as decisões desse governo.

Não é por acaso, que o Programa Criança Feliz desde o governo anterior vem recebendo um valor muito superior ao montante de recursos financeiros destinados aos programas, projetos e ações de gestão no âmbito do SUAS, que correspondem a direitos sociais previstos em lei (CFESS, 2018).Esse Programa, ao fortalecer o chamado "terceiro setor", promover a caridade e a filantropia, acentuar a precarização das condições e relações de trabalho, como incentivo o trabalho voluntário e a contratação de "visitadores sociais" por meio de entidades sociais, vem se desenvolvendo na contramão dos princípios e diretrizes da Lei Orgânica de Assistência Social e da PNAS/SUAS.

A ampliação do Programa Criança Feliz e a proposta inicial do governo (motivada também por questões político-eleitoreiras) de criação de um novo programa de renda mínima chamado de Renda Brasil, que surgiria da unificação do Programa Bolsa Família, como o Auxilio Emergencial criado no período da pandemia e de outros programas existentes no âmbito do governo nacional, também indicam que o governo orienta-se por uma concepção de assistência social como ajuda, que desconsidera a necessidade de uma política social que seja implementada por meio de um sistema descentralização e participativo. Pelo contrário, para esse governo ultraneoliberal, a área da assistência social deve se concentrar ape- 
nas na criação e implementação de programas focalizados na pobreza absoluta, como os programas de renda mínima, que não venham a restringir a liberdade do mercado; e em outras ações que, sob a gestão do primeiro-damismo, estimule as parcerias, o voluntariado, ou seja, que promovam a caridade e a filantropia.

\section{Considerações finais}

Em suma, pôde-se notar, com este capítulo, que em resposta à crise estrutural do capital a dinâmica da neoliberalização no Brasil vem exigindo uma determinada configuração do Estado, na qual não há espaço para proteção social pública e universal da população. Em que pese às resistências dos setores democráticopopulares, a análise dos governos (ultra)neoliberais e dos seus ataques à seguridade social demonstrou que a reedição e/ou o fortalecimento de velhas práticas, como a privatização, mercantilização dos serviços sociais e a filantropização da chamada "questão social", vem impondo limites à materialização desse padrão de proteção social previsto na Constituição Federal de 1988 e em outros dispositivos legais.

Em razão dessa ofensiva (ultra)neoliberal no âmbito da seguridade social, o que se vislumbra é o aprofundamento da tendência que tem sido chamada de assistencialização da proteção social ou da pobreza, que vem acompanhada do incentivo legal e financeiro por parte do Estado às formas de "proteção social" privada: mercantil exercida pelo mercado através da compra de serviços sociais; e nãomercantil desenvolvida pelas instituições tradicionais, como as famílias, associações, organizações sociais, entidades de caridade e de filantropia. A consequência desse formato de "proteção social" é o desmonte das políticas públicas que buscam materializar os direitos sociais.

Por essa razão, os partidos verdadeiramente de esquerda, os movimentos sociais, sindicatos e entidades profissionais comprometidos com os interesses da classe trabalhadora vêm defendendo ${ }^{7}$ : a se-

\footnotetext{
${ }^{7}$ Destaca-se aqui a Frente Nacional Contra a Privatização da Saúde (2017); o Conselho Federal de Serviço Social (CFESS, 2008); o Programa da Coligação Vamos Sem Medo de Mudar o
} 
guridade social pública e universal; a criação de um programa de renda universal de cidadania; a ampliação e mudanças nos critérios e testes vexatórios de acesso ao BPC; o fortalecimento dos espaços de participação e controle social democrático (fóruns, conselhos, conferências etc.); a revogação do teto dos gastos sociais(da EC95/2016), da DRU, da LRF e de outros mecanismos de ajuste fiscal, das leis que criaram as OSs, Fundações Estatais de Direito Privado, EBSERH e Parcerias Público-privadas, da Lei da Terceirização, das contrarreformas trabalhista e previdenciária; e têm sido contra a qualquer proposta de contrarreforma que restrinja direitos, como atual proposta de contrarreforma administrativa do governo Bolsonaro.

\section{Referências}

\section{ANTUNES, R.. A desertificação neoliberal no Brasil (Collor, FHC e} Lula). Campinas: São Paulo: Autores Associados, 2005.

. O privilégio da servidão: o novo proletariado de serviços na era digital. São Paulo: Boitempo, 2018.

BEHRING, E. R.Brasil em contra-reforma: desestruturação do Estado e perda de direitos. São Paulo: Cortez, 2003.

. A dívida e o calvário do fundo público. ADVIR (ASDUERJ), Rio de Janeiro, v. 36, 2017.

. BOSCHETTI, I. Política social: fundamentos e história, São

Paulo: Cortez, 2006.

BRAVO, M. I. S. A política de saúde no Brasil: trajetória histórica. In: Capacitação para conselheiros de saúde: textos de apoio. 1. ed. Rio de Janeiro: UERJ/DEPEXT/NAPE, 2001.

\footnotetext{
Brasil: Guilherme Boulos e Sonia Guajajara, da aliança que envolve Partido Socialismo e Liberdade (PSOL), Partido Comunista Brasileiro (PCB), Movimento dos Trabalhadores Sem Teto (MTST), Articulação dos Povos Indígenas do Brasil (APIB), Mídia Ninja e vários outros movimentos sociais (PARTIDO SOCIALISMO E LIBERDADE; PARTIDO COMUNISTA BRASILEIRO, 2018).
} 
. Política de saúde no Brasil. In: MOTA, A. E. et al. (org.). Serviço social e saúde: formação e trabalho profissional. São Paulo: OPAS; OMS; Ministério da Saúde, 2006.

et al. A saúde nos governos Temer e Bolsonaro: lutas e resistências. In: SER social (Online), v. 22, p. 191-209, 2020. et al. As contrarreformas na política de saúde do governo Temer. In: Argum., Vitória, v. 10, n. 1, p. 9-23, jan./abr. 2018.

CARCANHOLO, M. D. Neoliberalismo e o Consenso de Washington: a verdadeira concepção de desenvolvimento do Governo de FHC. In: MALAGUTI, M. L.; CARCANHOLO, R.; CARCANHOLO, M. D. (orgs.). Neoliberalismo: a tragédia do nosso tempo. São Paulo: Cortez, 1998.

CASTELO, R.O Canto da serei: social-liberalismo, novo desenvolvimentismo e supremacia burguesa no capitalismo dependente brasileiro. In: Revista Em Pauta, Rio de Janeiro, UERJ, n. 31, v. 11, 2013.

CFESS-CRESS. Carta de Maceió. Brasília: CFESS, 2000.

CFESS. Em defesa da política de assistência social e do trabalho de assistentes sociais. In: CFESS Manifesta, Brasília, 2018. Disponível em: <http://www.cfess.org.br/arquivos/2018-CfessManifesta-2SeminarioAssistencia-Site.pdf> . Acesso em: 13 set. 2020.

CISLAGHI, J. F. Parte III: O ultraneoliberalismo e a política dos ressentidos. Esquerda Online, Rio de Janeiro, 25 jun. 2020. Disponível em: <https://esquerdaonline.com.br/colunistas/juliana-fiuza-cislaghi/>. Acesso em: 24 jul. 2020.

CONGEMAS. Posicionamento do CONGEMAS acerca da Portaria ํㅡ 2.362. CONGEMAS, Brasília, 12 fev. 2020. Disponível em: <http:// www.congemas.org.br/Publicacao.aspx?id=112428>. Acesso em: 24 jul. 2020.

COUTINHO, C. N. Gramsci: um estudo sobre seu pensamento político. Rio de Janeiro: Campus, 1992.

Contra a corrente: ensaios sobre democracia e socialismo. São Paulo: Cortez, 2008. 
DRUCK, G. Trabalho, precarização e resistências: novos e velhos desafios? In: Caderno CRH, Salvador, v. 24, n. spe 01, p. 37-57, 2011.

FERNANDES, F. Pensamento e ação: o PT e os rumos do socialismo. São Paulo: Globo, 2006.

FLEURY, S. O golpe na Saúde. CEBES, Rio de Janeiro, 13 jun. 2020. Disponível em: <http://cebes.org.br/2020/06/o-golpe-na-saude/>. Acesso: 13 set. 2020 .

FOLHA DE SÃO PAULO. Mesmo após 'bronca' de Bolsonaro, governo publica portaria para rever BPC. São Paulo, 17 set. 2020. Disponível em: <https://www1.folha.uol.com.br/mercado/2020/09/mesmoapos-bronca-de-bolsonaro-governo-publica-portaria-para-reverbpc.shtml>. Acesso em: 19 set. 2020.

Bolsonaro não prevê novos atendidos pelo Bolsa Família em 2020. São Paulo, 2 dez. 2019. Disponível em: <https://www1.foIha.uol.com.br/mercado/2019/12/governo-bolsonaro-nao-prevenovos-atendidos-pelo-bolsa-familia-em-2020>. Acesso em: 19 set. 2020.

FONTES, V. O núcleo central do governo Bolsonaro - o proto-fascismo. Esquerda online, Rio de Janeiro, 08 jan. 2019. Disponível em: <https://esquerdaonline.com.br/2019/01/08/o-nucleo-central-dogoverno-bolsonaro-o-proto-fascismo/> . Acesso: 13 set. 2020.

FRASER, N.; JAEGGI, R. Capitalismo em debate: uma conversa na teoria crítica. São Paulo: Boitempo, 2020.

FRENTE NACIONAL CONTRA A PRIVATIZAÇÃO DA SAÚDE. Relatório e síntese de Propostas. VII Seminário da Frente Nacional contra a Privatização da Saúde. Disponível em: <https://drive.google.com/file/ d/1H-ZEjL6KCHk2rATzW_2nppK4oDSC9okB/edit>. Acesso em: $20 \mathrm{fev}$. 2018.

GRANEMANN, S. Para uma interpretação marxista da 'previdência privada'. Rio de Janeiro, 2006. Tese (Doutorado em Serviço Social) Escola de Serviço Social, Universidade Federal do Rio de Janeiro, Rio de Janeiro, 2006. 
HARVEY, D. O neoliberalismo: história e implicações. São Paulo: Edições Loyola, 2008.

IAMAMOTO, M. V. Os espaços sócio-ocupacionais do assistente social. In: Serviço social: direitos sociais e competências profissionais. Brasília: CFESS/ABEPSS, 2009.

IASI, M. L. O fascismo e os "homens bons". Blog da Boitempo, São Paulo, 16 out. 2018. Disponivel em: <https://blogdaboitempo.com.br/2018/10/16/o-fascismo-e-os-homens-bons/>. Acesso em: 1 mar. 2019.

MOTA, A. E. Cultura da crise e seguridade social: um estudo sobre as tendências da previdência e da assistência social brasileira nos anos 80 e 90. São Paulo: Cortez, 2000.

NETTO, J. P. Democracia e transição socialista: escritos de teoria e política. Belo Horizonte: Oficina de Livros, 1990.

. FHC e a política social: um desastre para as massas trabalhadoras. In: LESBAUPIN, Ivo (org.). 0 desmonte da nação: balanço do Governo FHC. Petrópolis: Rio de Janeiro: Vozes, 1999.

PARTIDO DOS TRABALHADORES. Programa de Governo 2002 coligação Lula presidente. São Paulo: Fundação Perseu Abramo, 2002.

PARTIDO SOCIALISMO E LIBERDADE; PARTIDO COMUNISTA BRASILEIRO. Programa da coligação Vamos Sem Medo de Mudar o Brasil. [S. I.]: PSOL: PCB, 2018. Disponível em: <http://divulgacandcontas.tse.jus.br/candidaturas/oficial/2018/BR/BR/ 2022802018/280000601016/proposta_1533565462424.pdf> . Acesso em: 20 set. 2020.

RODRIGUES, M. Assistência social e vanguardas do serviço social na era neoliberal. In: Argum. Vitória, v. 8, n. 2, p. 35-50, maio/ago. 2016. SILVA, R. R. da. (Des)centralização, contrarreforma do Estado e política de assistência social no Brasil. 2014. Tese (Doutorado em Serviço Social) -Escola de Serviço Social da Universidade Federal do Rio de Janeiro, Rio de Janeiro, 2014. 
TEIXEIRA, A. M. de P. Previdência social no Brasil: da revolução passiva à contra-reforma. Rio de Janeiro, 2006. Tese (Doutorado em Serviço Social) - Escola de Serviço Social, Universidade Federal do Rio de Janeiro, Rio de Janeiro, 2006.

\section{Sobre o autor}

Robson Roberto da Silva - Assistente social e mestre em Política Social pela UFF. Especialista em Serviço Social, Direitos Sociais e Competências Profissionais pela UNB. Doutor em Serviço Social pela UFRJ. Pós-doutor em Serviço Social pela UERJ. Professor adjunto da Escola de Serviço Social da UFF Niterói. Coordenador do Grupo de Estudos e Pesquisas em Desenvolvimento Capitalista, Trabalho e Política Social (GPODE). E-mail: robson.essuff@gmail.com 